\title{
Pakistan's Ranking in Social Development: Have We Always Been Backward?
}

\author{
Aisha GHAUS-PASHA and NAEEM AHMED
}

Consensus is emerging between development thinkers and practitioners that social progress is a necessary pre-condition for sustained economic growth. Social development leads to higher levels of literacy, better health standards and overall improvement in the society's living conditions. In fact, empirical evidence suggests that there is a two-way relationship between economic growth and social development [Ghaus-Pasha et al. (1998)]. Economic growth leads to higher revenues for government and higher per capita income, encouraging both public and private spendings on human development. Improvements in social indicators feedback as higher economic growth through enhanced productivity for labour and capital. In other words, well-developed human capital makes a significant contribution to economic growth which, in turn, offers improved welfare and better living conditions.

However, if there is a breakdown in this chain and economic development is not translated into social development, then the pace of economic development eventually suffers. Pakistan is an example of a country where this chain has broken. Despite moderate economic growth of about 5 percent during the last decade or so, the state of social indicators leaves a lot to be desired. Currently, the female literacy rate is 33 percent, being somewhat higher for males at 56 percent; primary school enrolment for females is 55 percent, for males 78 percent; and infant mortality rate is 105 out of 1000 . Today, Pakistan is ranked 138 in the human development index by the UNDP (1999) among 174 countries.

The purpose of this paper is to see the state of social development in Pakistan in the international context. A key objective is to see whether the current low level of social indicators is largely a consequence of poor initial conditions or is it due to

Aisha Ghaus-Pasha and Naeem Ahmed are Deputy Managing Director and Research Officer respectively at the Social Policy and Development Centre, Karachi.

Authors' Note: The authors acknowledge the comments of Dr Hafiz A. Pasha. Any errors or omissions remain the responsibility of the authors. 
relatively low rate of improvement over time in comparison to other countries? For this purpose we analyse the long-term evolution of social development from 1960 to 1995 using international cross-sectional data on a number of indicators. The sample includes developing countries with relatively low per capita income (below $\$ 400$ ) and relatively large populations (above 8 million) in 1960. Twenty five countries satisfy this criteria: five from South Asia, seven from other parts of Asia, four from Latin America and nine from Africa. Development ranking of these 25 countries has been generated for 1960, 1970, 1980, 1990 and 1995.

The paper is organised as follows: Section 2 of the paper discusses the choice of the indicators included in the analysis. Section 3 describes the choice of technique used for developing the rankings of countries. The resulting rankings are presented in Section 4, while Section 5 describes proxies of social development. Evolution in Pakistan's ranking is presented in Section 6. Finally, Section 7 summarises the main findings of the paper.

\section{CHOICE OF INDICATORS}

The human development index (HDI), first published in the UNDP report of 1990 , relies on three main indicators to measure the extent of human development in a country. These include income, educational attainment (proxied by literacy rate and combined enrolment rate) and life expectancy. HDI is the most widely used composite index of human development. As such, for the purpose of the crosscountry analysis in this report we rely on the same output indicators, with one key exception. Instead of just relying on life expectancy at birth to reflect the state of health of the people in a country, we additionally use infant mortality rate.

In the Human Development Report of 1993 it is argued that infant mortality rate is essentially complementary and highly correlated with life expectancy. However, according to our analysis the rank correlation between life expectancy and infant mortality for the sample countries was only 0.64 in 1960 and 0.85 in 1970, reflecting that in the case of developing countries, the high correlation may not necessarily hold. Therefore, we use both infant mortality rate and life expectancy in the analysis.

To cover the level of educational attainment we select three indicators-adult literacy, primary enrolment rate, and secondary enrolment rate. The literacy rate is a stock measure and is fraught with problem of differences in definition among countries. Therefore, we additionally use two flow measures of primary and secondary enrolment rates. GNP per capita adjusted for purchasing power parity differences in US \$ is used to construct the income index.

\section{CHOICE OF TECHNIQUE}

A number of techniques have been used in the relevant literature for measuring and computing a composite index of human development. The first is the Z-sum 
technique which is the sum for a particular country for its Z-score on each indicator. The $Z$-score is the standardized score, which has zero mean and unit variance. The higher the Z-sum the more developed the country. The second technique computes the taxonomic distance [Noorbakhsh $(1998,1998 \mathrm{a})$ ], which is the Euclidean distance from the highest (standardised) values observed for different indicators. The lower the taxonomic distance of a country, the better its position.

The third technique, used for the construction of the HDI, is the unweighted average of the relative distance. This distance is the difference between the actual value of the variable in a country and a minimum value divided by the range of the variable, that is, the difference between the maximum and the minimum values. All three techniques have the problem of assigning equal weight to each development indicator. Further, the taxonomic distance technique is very sensitive to the presence of outliers.

The fourth and the most sophisticated method for indexing a multidimensional phenomenon is the factor analysis (FA) technique [Adelman and Dalton (1971)]. The essential purpose of factor analysis is to describe, if possible, the covariance relationships among many variables in terms of a few underlying, but unobservable, random quantities called factors. Thus the factor analysis model can be described as follows:

$$
X_{i}=a_{i 1} F_{1}+a_{i 2} F_{2}+\ldots+a_{i j} F_{j} \quad \ldots \quad \ldots \quad \ldots \quad \ldots
$$

Where,

$X_{i}$ is the $i$ th indicator.

$a_{i j}$ is called the factor loading and represents the proportion of the variation in $\mathrm{X}_{i}$ which is accounted for by the $j$ th factor.

$\sum a_{i j}^{2}$ is called the communality and it is equivalent to the multiple regression coefficient in regression analysis.

$F_{j}$ represents $j$ th factor of component.

Principal Components Analysis (PCA) produces components in descending order of importance, that is, the first component explains the maximum amount of variation in the data, and the last component the minimum. It is often found that the first few components, called principal components, account for a sizeable part of the variation and subsequent components contribute very little. Using factor loadings of these principal components, factor score for each country or unit is computed as follows:

$$
\begin{array}{lllllll}
(\mathrm{FS})_{k j}=\sum_{k} a_{i j} * \mathrm{Z}_{i} & \ldots & \ldots & \ldots & \ldots & \ldots & \ldots
\end{array}
$$

Where,

$\mathrm{FS}_{k j}$ represents factor score of the $k$ th country and the $j$ th factor. 
$Z_{i}$ is the standardised value of the $i$ th indicator.

$a_{i j}$ is the factor loading of the $j$ th factor and the $i$ th indicator.

To compute weighted factor score (WFS), these individual factor scores are derived from the following equation:

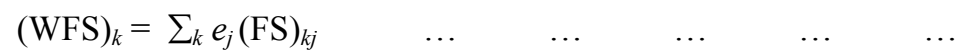

Where $e_{j}$ is the eigen value of the factor $j$ and depicts the proportion of variation in the data set explained by the factor $j$. This WFS is used as an index for ranking countries on the basis of the general characteristics of the variable-set. This technique has increasingly been used in literature [Ghaus-Pasha et al. (1996); Pasha and Hasan et al. (1982); Pasha et al. (1990); Ogwan (1994); Jamal and Malik (1988)].

In this study, principal components analysis is preferred to transform the indicators into a composite index and the weighted factor score is used to rank the country due to its more appealing characteristics. However, the Z-sum technique is also used, to determine the sensitiveness of the results with respect to the choice of technique for deriving the composite indicator.

Table 1 presents the loadings of each indicator on different factors for each of the years analysed. Some important conclusions emerge. First, infant mortality rate is the only indicator which has consistently loaded on the first factor in all the years analysed. This highlights the importance of this indicator in explaining variations in the level of social development across countries. The inclusion of this indicator in the analysis is, therefore, justified. Second, health related indicators generally dominate the first factor. Data on the indicators, magnitude of weighted factor score and $Z$-sum score for each country are presented in Appendices.

\section{RANKING OF COUNTRIES IN TERMS OF SOCIAL DEVELOPMENT}

Currently Korea, Sri Lanka, Colombia, Mexico and Thailand are the five most socially developed countries in the sample. (See Table 2). Three of these, Mexico, Sri Lanka and Korea have been in the top five countries throughout the last three decades. Philippines and Peru, which ranked fourth and fifth respectively in 1960, have slipped down to the sixth and seventh rank by 1995. Colombia has climbed up the ladder from six to three during the period of analysis. The fact that Korea and Thailand started with relatively favourable initial positions in 1960 partly explains their spectacular performance subsequently.

The five least developed countries in terms of human development include Afghanistan, Ethiopia, Sudan, Tanzania and Zaire. The countries which have progressed significantly from the bottom during the period of analysis are Nigeria and Nepal. Countries which have experienced a major deterioration in their rank include Zaire and Sudan. 
Table 1

Factor Loading Matrix

\begin{tabular}{|c|c|c|c|c|}
\hline Variables & Factor I & Factor II & Factor III & Communality \\
\hline & {$\left[\begin{array}{llllll}1 & 96 & 60 & 0\end{array}\right]$} & & & \\
\hline Inverse of Infant Mortality Rate & 0.910 & 0.348 & 0.024 & 0.950 \\
\hline Life Expectancy at Birth & 0.725 & 0.426 & 0.442 & 0.903 \\
\hline Adult Literacy & 0.673 & 0.618 & 0.265 & 0.905 \\
\hline School Enrolment, Secondary & 0.328 & 0.888 & 0.130 & 0.914 \\
\hline School Enrolment, Primary & 0.544 & 0.722 & 0.247 & 0.879 \\
\hline GNP Per Capita & 0.125 & 0.155 & 0.973 & 0.987 \\
\hline Percentage of Variation Explained & 71.8 & 14.2 & 6.3 & \\
\hline Eigen Value & $\begin{array}{c}4.308 \\
{\left[\begin{array}{c}1970 \\
\end{array}\right]}\end{array}$ & 0.854 & 0.374 & \\
\hline Inverse of Infant Mortality Rate & 0.916 & 0.139 & 0.324 & 0.963 \\
\hline Adult Literacy & 0.727 & 0.424 & 0.448 & 0.908 \\
\hline Life Expectancy at Birth & 0.674 & 0.533 & 0.416 & 0.911 \\
\hline GNP Per Capita & 0.194 & 0.941 & 0.204 & 0.964 \\
\hline School Enrolment, Secondary & 0.412 & 0.215 & 0.859 & 0.955 \\
\hline School Enrolment, Primary & 0.414 & 0.556 & 0.635 & 0.884 \\
\hline Percentage of Variation Explained & 76.5 & 11 & 5.6 & \\
\hline \multirow[t]{2}{*}{ Eigen Value } & 4.59 & 0.66 & 0.336 & \\
\hline & {$\left[\begin{array}{llll}1 & 9 & 80 & 0\end{array}\right]$} & & & \\
\hline Inverse of Infant Mortality Rate & 0.889 & 0.247 & 0.292 & 0.936 \\
\hline School Enrolment, Secondary & 0.685 & 0.536 & 0.248 & 0.817 \\
\hline GNP Per Capita & 0.247 & 0.917 & 0.247 & 0.963 \\
\hline Life Expectancy at Birth & 0.511 & 0.689 & 0.415 & 0.908 \\
\hline School Enrolment, Primary & 0.235 & 0.266 & 0.909 & 0.951 \\
\hline Adult Literacy & 0.575 & 0.309 & 0.657 & 0.857 \\
\hline Percentage of Variation Explained & 73.32 & 9.45 & 7.78 & \\
\hline \multirow[t]{2}{*}{ Eigen Value } & 4.399 & 0.567 & 0.467 & \\
\hline & {$\left[\begin{array}{llll}19 & 9 & 9 & 0\end{array}\right]$} & & & \\
\hline Inverse of Infant Mortality Rate & 0.897 & 0.262 & 0.204 & 0.914 \\
\hline GNP Per Capita & 0.651 & 0.449 & 0.375 & 0.767 \\
\hline School Enrolment, Secondary & 0.408 & 0.854 & 0.197 & 0.935 \\
\hline Life Expectancy at Birth & 0.547 & 0.612 & 0.501 & 0.925 \\
\hline Adult Literacy & 0.537 & 0.160 & 0.797 & 0.949 \\
\hline School Enrolment, Primary & 0.081 & 0.648 & 0.728 & 0.956 \\
\hline Percentage of Variation Explained & 73.88 & 9.74 & 7.15 & \\
\hline \multirow[t]{2}{*}{ Eigen Value } & 4.432 & 0.584 & 0.429 & \\
\hline & {$\left[\begin{array}{lll}1 & 995\end{array}\right]$} & & & \\
\hline School Enrolment, Secondary & 0.855 & 0.388 & 0.078 & 0.887 \\
\hline Inverse of Infant Mortality Rate & 0.794 & 0.064 & 0.490 & 0.875 \\
\hline GNP Per Capita & 0.699 & 0.283 & 0.527 & 0.846 \\
\hline School Enrolment, Primary & 0.197 & 0.920 & 0.261 & 0.953 \\
\hline Life Expectancy at Birth & 0.566 & 0.641 & 0.410 & 0.899 \\
\hline Adult Literacy & 0.270 & 0.396 & 0.828 & 0.916 \\
\hline Percentage of Variation Explained & 70.9 & 11.57 & 7.13 & \\
\hline Eigen Value & 4.253 & 0.694 & 0.428 & \\
\hline
\end{tabular}


Table 2

Social Development Ranking of Countries, 1960-1995 Ranking by Factor Analysis

\begin{tabular}{lccccc}
\hline Countries $^{\mathrm{a}}$ & 1960 & 1970 & 1980 & 1990 & 1995 \\
\hline Mexico & 1 & 3 & 2 & 3 & 4 \\
Sri Lanka & 2 & 2 & 4 & 2 & 2 \\
Korea & 3 & 1 & 1 & 1 & 1 \\
Philippines & 4 & 4 & 5 & 5 & 6 \\
Peru & 5 & 6 & 6 & 9 & 7 \\
Colombia & 6 & 5 & 3 & 4 & 3 \\
Brazil & 7 & 8 & 8 & 8 & 9 \\
Thailand & 8 & 9 & 7 & 7 & 5 \\
Turkey & 9 & 7 & 9 & 6 & 8 \\
Iran & 10 & 10 & 10 & 12 & 11 \\
Algeria & 11 & 12 & 12 & 11 & 12 \\
India & 12 & 14 & 18 & 15 & 15 \\
Egypt & 13 & 11 & 14 & 13 & 13 \\
Indonesia & 14 & 13 & 11 & 10 & 10 \\
Morocco & 15 & 15 & 15 & 16 & 16 \\
Bangladesh & 16 & 19 & 21 & 21 & 20 \\
Pakistan & $\mathbf{1 7}$ & $\mathbf{1 8}$ & $\mathbf{2 3}$ & $\mathbf{2 2}$ & $\mathbf{1 8}$ \\
Zaire & 18 & 17 & 19 & 18 & 21 \\
Kenya & 19 & 16 & 13 & 14 & 14 \\
Sudan & 20 & 20 & 22 & 23 & 23 \\
Nigeria & 21 & 22 & 16 & 17 & 17 \\
Tanzania & 22 & 21 & 17 & 20 & 22 \\
Nepal & 23 & 23 & 20 & 19 & 19 \\
Ethiopia & 24 & 25 & 25 & 24 & 24 \\
Afghanistan & 25 & 24 & 24 & 25 & 25 \\
\hline
\end{tabular}

${ }^{\mathrm{a}}$ Given in descending order in 1960.

An interesting result is the robustness of top rankings, countries in the first nine positions in 1960 are the same in 1995 . Therefore, one can draw the conclusion that if a country starts with an advantage in human endowment, it is easier to maintain its relative position. Most of the volatility in rankings is observed among countries at lower initial positions.

It appears that the ranking of countries is not sensitive to the choice of technique used for estimation. This is demonstrated by Table 3 . There is a very high

Table 3

Correlation of Countries Rankings Obtained from Different Techniques

\begin{tabular}{lcc}
\hline & \multicolumn{2}{c}{ Rank Correlation Coefficient } \\
\cline { 2 - 3 } Years & Factor Analysis and & Factor Analysis and \\
Z-Sum Technique & HDI \\
\hline 1960 & 0.911 & 0.989 \\
1970 & 0.944 & 0.980 \\
1980 & 0.997 & 0.975 \\
1990 & 0.988 & 0.965 \\
1995 & 0.990 & 0.936 \\
\hline
\end{tabular}


correlation ranging from 0.91 to 0.99 between the ranking of countries obtained using factor analysis and Z-sum scores. The robustness of the results is also illustrated by the high degree of correlation (0.936-0.989) between our ranking and the HDI ranking of UNDP. Table 4 presents ranking of countries using Z-sum scores.

Table 4

Social Development Ranking of Countries 1960-95 Ranking by Z-Sum Score

\begin{tabular}{lccccc}
\hline Countries & 1960 & 1970 & 1980 & 1990 & 1995 \\
\hline Mexico & 2 & 3 & 2 & 3 & 4 \\
Sri Lanka & 1 & 2 & 3 & 2 & 2 \\
Korea & 3 & 1 & 1 & 1 & 1 \\
Philippines & 4 & 4 & 5 & 5 & 6 \\
Peru & 8 & 6 & 6 & 9 & 7 \\
Colombia & 5 & 5 & 4 & 4 & 3 \\
Brazil & 6 & 8 & 8 & 8 & 11 \\
Thailand & 7 & 7 & 7 & 6 & 5 \\
Turkey & 9 & 9 & 9 & 7 & 8 \\
Iran & 10 & 10 & 10 & 12 & 10 \\
Algeria & 13 & 13 & 12 & 10 & 9 \\
India & 12 & 14 & 17 & 15 & 14 \\
Egypt & 11 & 11 & 14 & 13 & 13 \\
Indonesia & 14 & 12 & 11 & 11 & 12 \\
Morocco & 15 & 16 & 15 & 16 & 15 \\
Bangladesh & 16 & 19 & 21 & 20 & 20 \\
Pakistan & $\mathbf{1 7}$ & $\mathbf{1 8}$ & $\mathbf{2 3}$ & $\mathbf{2 2}$ & $\mathbf{1 9}$ \\
Zaire & 18 & 17 & 18 & 18 & 21 \\
Kenya & 19 & 15 & 13 & 14 & 16 \\
Sudan & 21 & 21 & 22 & 23 & 23 \\
Nigeria & 20 & 22 & 16 & 17 & 17 \\
Tanzania & 22 & 20 & 19 & 21 & 22 \\
Nepal & 23 & 23 & 20 & 19 & 18 \\
Ethiopia & 24 & 24 & 25 & 24 & 24 \\
Afghanistan & 25 & 25 & 24 & 25 & 25 \\
\hline Presentin & 25 & 19 & \\
\hline
\end{tabular}

Presented in descending order according to the weighted factor score in 1960.

\section{PROXIES FOR SOCIAL DEVELOPMENT}

Variations in the composite human development index across countries are, to a great extent, due to variations in health related indicators - life expectancy and infant mortality rate followed by literacy rate. This is depicted by the high correlation between the composite index and these indicators (see Table 5). This conclusion is in line with the result of Ogwang-Tomson (1994) who suggested that life expectancy is a good proxy for social development. The relatively low value of the GNP per capita coefficient, as compared to health and education, indicates that income is not the best proxy for social development. 
Table 5

Rank Correlation between Composite Social Development Index and Individual Indicators

\begin{tabular}{lccccc}
\hline & 1960 & 1970 & 1980 & 1990 & 1995 \\
\hline Life Expectancy at Birth, Total & 0.873 & 0.941 & 0.922 & 0.959 & 0.937 \\
Inverse of Infant Mortality Rate & 0.694 & 0.838 & 0.895 & 0.938 & 0.936 \\
Adult Literacy & 0.889 & 0.889 & 0.894 & 0.887 & 0.882 \\
School Enrolment, Primary & 0.889 & 0.910 & 0.821 & 0.829 & 0.780 \\
School Enrolment, Secondary & 0.848 & 0.867 & 0.864 & 0.838 & 0.736 \\
GNP per Capita & 0.743 & 0.808 & 0.833 & 0.858 & 0.868 \\
\hline
\end{tabular}

\section{EVOLUTION OF PAKISTAN'S RANKING}

We next turn to the key question raised in this report. Is the low level of human development in the country due to the low initial endowments or has the condition exacerbated due to a relatively low rate of improvement overtime? Table 6 provides a clear answer to the question. Pakistan was relatively backward in 1960 with a ranking of 17. This ranking deteriorated further to 18 in 1970 and to 23 in 1980. Since then there has been some improvement with the ranking falling to 22 in 1990 and 18 in 1995. It appears that the Pakistani case is one of poorer initial conditions (in 1960) which have been clearly exacerbated by a low rate of improvement since then. In fact, our ranking in the international scenario has actually deteriorated over the period of analysis.

It appears that over the period Pakistan has maintained a fairly stable ranking as far as income is concerned. In all other indicators its ranking has deteriorated .The maximum decline has been in secondary school enrolment, infant mortality rate and adult literacy rate. The improvement in the aggregate ranking in the 90s appears to be a consequence of improvement in enrolment indicators, both primary and secondary, and life expectancy at birth.

Table 6

Pakistan's Ranking in Individual Indicators 1960 to 1995

\begin{tabular}{lccccc}
\hline & \multicolumn{5}{c}{ Ranking } \\
\cline { 2 - 6 } Indicators & 1960 & 1970 & 1980 & 1990 & 1995 \\
\hline Infant Mortality Rate & 15 & 17 & 21 & 20 & 21 \\
Life Expectancy at Birth & 14 & 15 & 17 & 17 & 15 \\
Adul Literacy Rate & 17 & 20 & 22 & 21 & 22 \\
School Enrolment, Primary & 20 & 19 & 23 & 23 & 20 \\
School Enrolment, Secondary & 11 & 14 & 22 & 21 & 19 \\
GNP per Capita (in PPP\$) & 15 & 14 & 14 & 15 & 15 \\
Overall Social Development Ranking & 17 & 18 & 23 & 22 & 18 \\
\hline
\end{tabular}


The low level of improvement in the social development indicators is a consequence of the lack of importance attached to human development historically by policy-makers in the country. Human development received a lot of rhetoric but no concrete priority in terms of policy framework for institutional strengthening or allocation of public resources. The Five Point Programme (FPP) initiated in the mid80 s was the first public sector programme which prioritised human development in the country. It constituted the first serious attempt at earmarking of resources and strengthening of infrastructure of social development in the history of Pakistan. The Social Action Programme (SAP) was the second major public sector initiative in this regard. The contribution of these programmes in uplifting the state of social development is reflected in the improvement visible in Pakistan's ranking in 1990 and 1995.

However, the nation has yet to recover the ground lost due to decades (60s and 70s in particular) of negligence. Pakistan's international standing in 1995 is worse than it was in 1960. This will require, first, continued public sector priority for the development of human resources in terms of concrete effort at improvement in delivery mechanisms, improved cost effectiveness of expenditures and higher budgetary resources for the sector. Second, civil society at large will have to play an active role both in enhancing awareness and understanding of the importance of human development and complementing the public sector in provision of social services.

\section{SUMMARY AND CONCLUSIONS}

The objectives of the report are twofold: first, to examine the international ranking of Pakistan in terms of social development and second, to see whether the low level of social indicators in the country is a consequence of poor initial conditions or has there been a deterioration due to relatively low rate of improvement overtime?

Using a sample of 25 developing countries and six basic social indicators relating to income, education and health, the analysis shows the current low rank of Pakistan, 18th out of 25 countries. The ranking has actually deteriorated from 17 in 1960. As such, the report concludes that Pakistan is a case of a country which not only started with a low level of human endowment but the situation has been exacerbated by the low level of improvement in it over time.

The lack of government priority for social sectors, both in terms of budgetary resources and institutional development is a basic cause of the current malaise. If the situation is to be improved, concrete government effort at improving delivery mechanisms, improved cost-effectiveness of expenditures and higher budgetary resources will have to be ensured. Moreover, civil society at large will have to play a complementary role both in terms of enhancing awareness levels and provision of social services. 
Appendices

Appendix A

Weighted Factor Score of Sample Countries

\begin{tabular}{lrrrrr}
\hline Countries & 1960 & 1970 & 1980 & 1990 & 1995 \\
\hline Mexico & 3.209 & 2.553 & 2.687 & 2.188 & 1.817 \\
Sri Lanka & 3.038 & 2.613 & 2.108 & 2.241 & 2.063 \\
Korea & 2.048 & 2.725 & 3.407 & 3.405 & 3.669 \\
Philippines & 2.008 & 2.256 & 1.752 & 1.470 & 1.335 \\
Peru & 1.924 & 1.736 & 1.533 & 1.210 & 1.290 \\
Colombia & 1.870 & 2.064 & 2.197 & 1.889 & 1.862 \\
Brazil & 1.547 & 1.307 & 1.270 & 1.249 & 1.139 \\
Thailand & 1.180 & 1.086 & 1.283 & 1.419 & 1.530 \\
Turkey & 1.025 & 1.467 & 0.737 & 1.425 & 1.178 \\
Iran & 1.006 & 0.842 & 0.606 & 0.481 & 0.863 \\
Algeria & 0.065 & -0.126 & 0.001 & 0.610 & 0.847 \\
India & -0.333 & -0.394 & -0.884 & -0.481 & -0.552 \\
Egypt & -0.360 & 0.150 & -0.383 & 0.158 & 0.069 \\
Indonesia & -0.647 & -0.255 & 0.138 & 0.657 & 0.887 \\
Morocco & -0.980 & -0.912 & -0.598 & -0.582 & -0.692 \\
Bangladesh & -1.034 & -1.336 & -1.699 & -1.652 & -1.428 \\
Pakistan & $-\mathbf{1 . 1 1 8}$ & $-\mathbf{1 . 2 3 5}$ & $-\mathbf{1 . 9 0 8}$ & $-\mathbf{1 . 7 6 7}$ & $-\mathbf{1 . 3 5 1}$ \\
Zaire & -1.272 & -1.112 & -0.938 & -1.188 & -1.498 \\
Kenya & -1.340 & -0.918 & -0.181 & -0.378 & -0.478 \\
Sudan & -1.552 & -1.744 & -1.857 & -2.220 & -2.113 \\
Nigeria & -1.623 & -1.863 & -0.745 & -1.178 & -1.202 \\
Tanzania & -2.027 & -1.838 & -0.858 & -1.613 & -1.711 \\
Nepal & -2.091 & -2.113 & -1.646 & -1.349 & -1.415 \\
Ethiopia & -2.194 & -2.558 & -3.030 & -2.810 & -2.779 \\
Afghanistan & -2.347 & -2.395 & -2.991 & -3.183 & -3.331 \\
\hline & & & & & \\
\hline
\end{tabular}

Appendix B

Z-Sum of Indicators for Sample Countries

\begin{tabular}{lccccc}
\hline Countries & 1960 & 1970 & 1980 & 1990 & 1995 \\
\hline Sri Lanka & 10.402 & 8.446 & 6.585 & 6.994 & 6.315 \\
Mexico & 7.786 & 7.621 & 7.764 & 6.385 & 4.816 \\
Korea & 7.720 & 9.155 & 10.847 & 10.775 & 12.114 \\
Philippines & 6.739 & 6.864 & 5.275 & 4.315 & 3.746 \\
Colombia & 5.025 & 6.281 & 6.376 & 5.657 & 5.245 \\
Brazil & 4.469 & 3.851 & 3.602 & 3.450 & 2.658 \\
Thailand & 4.159 & 3.921 & 3.772 & 4.216 & 4.023 \\
Peru & 4.049 & 4.602 & 4.431 & 3.378 & 3.477 \\
Turkey & 1.858 & 3.528 & 1.945 & 4.025 & 3.014 \\
Iran & 0.880 & 1.964 & 1.779 & 1.328 & 2.712 \\
Egypt & -0.205 & 0.138 & -0.917 & 0.639 & 0.920 \\
India & -0.428 & -1.446 & -2.710 & -1.550 & -1.496 \\
Algeria & -1.027 & -0.778 & -0.082 & 1.775 & 2.760 \\
Indonesia & -1.523 & -0.773 & 0.127 & 1.702 & 1.917 \\
Morocco & -2.835 & -2.728 & -1.802 & -1.679 & -1.768 \\
Bangladesh & -2.988 & -4.197 & -4.983 & -4.945 & -4.331 \\
Pakistan & $-\mathbf{3 . 0 4 9}$ & $-\mathbf{3 . 6 8 1}$ & $-\mathbf{5 . 4 0 2}$ & $-\mathbf{5 . 1 0 4}$ & $-\mathbf{3 . 8 9 3}$ \\
Zaire & -3.134 & -3.563 & -2.951 & -3.701 & -4.829 \\
Kenya & -3.455 & -2.500 & -0.835 & -1.387 & -2.204 \\
Nigeria & -4.701 & -5.449 & -2.506 & -3.573 & -3.744 \\
Sudan & -4.742 & -5.218 & -5.263 & -6.372 & -6.269 \\
Tanzania & -5.369 & -5.033 & -2.999 & -5.032 & -5.804 \\
Nepal & -6.047 & -6.326 & -4.941 & -4.024 & -3.745 \\
Ethiopia & -6.268 & -7.332 & -8.615 & -8.139 & -6.536 \\
Afghanistan & -7.317 & -7.347 & -8.495 & -9.132 & -9.097 \\
\hline & & & & & \\
\hline
\end{tabular}


Appendix C

Literacy Rate in Sample Countries

\begin{tabular}{lccccc}
\hline Countries & 1960 & 1970 & 1980 & 1990 & 1995 \\
\hline Mexico & 65.4 & 74.2 & 82.7 & 87.3 & 89.6 \\
Sri Lanka & 75.0 & 77.6 & 85.0 & 88.4 & 90.2 \\
Korea & 70.0 & 87.6 & 93.0 & 93.0 & 98.0 \\
Philippines & 71.9 & 82.6 & 86.2 & 89.7 & 94.6 \\
Peru & 61.0 & 70.4 & 80.0 & 85.1 & 88.7 \\
Colombia & 63.0 & 75.9 & 81.0 & 86.7 & 91.3 \\
Brazil & 61.0 & 66.2 & 76.0 & 81.1 & 83.3 \\
Thailand & 67.7 & 78.6 & 86.0 & 93.0 & 93.8 \\
Turkey & 38.0 & 51.3 & 60.0 & 80.7 & 82.3 \\
Iran & 16.0 & 36.9 & 50.0 & 54.0 & 72.1 \\
Algeria & 13.4 & 26.4 & 35.0 & 57.4 & 61.6 \\
India & 27.8 & 34.1 & 36.0 & 48.2 & 52.0 \\
Egypt & 25.8 & 33.0 & 44.0 & 48.4 & 51.4 \\
Indonesia & 39.0 & 56.6 & 65.5 & 77.0 & 83.8 \\
Morocco & 13.8 & 21.4 & 28.0 & 49.5 & 43.7 \\
Bangladesh & 21.6 & 23.0 & 27.9 & 35.3 & 38.1 \\
Pakistan & $\mathbf{1 5 . 4}$ & $\mathbf{2 0 . 7}$ & $\mathbf{2 4 . 0}$ & $\mathbf{3 4 . 8}$ & $\mathbf{3 7 . 8}$ \\
Zaire & 31.3 & 13.0 & 54.5 & 72.0 & 67.0 \\
Kenya & 19.5 & 30.0 & 47.1 & 69.0 & 78.1 \\
Sudan & 13.1 & 16.6 & 32.0 & 27.1 & 46.1 \\
Nigeria & 15.4 & 21.9 & 34.0 & 50.7 & 57.1 \\
Tanzania & 9.5 & 37.4 & 79.0 & 72.1 & 67.8 \\
Nepal & 8.8 & 14.3 & 19.0 & 25.6 & 27.5 \\
Ethiopia & 6.0 & 9.4 & 15.0 & 29.4 & 35.5 \\
Afghanistan & 8.0 & 10.0 & 20.0 & 29.4 & 31.5 \\
\hline & & & & \\
\end{tabular}

Secondary School Enrolment in Sample Countries

\begin{tabular}{|c|c|c|c|c|c|}
\hline$\overline{\text { Mexico }}$ & 11 & 22 & 48 & 55 & 58 \\
\hline Sri Lanka & 27 & 47 & 55 & 74 & 75 \\
\hline Korea & 25 & 42 & 78 & 90 & 101 \\
\hline Philippines & 26 & 46 & 64 & 73 & 79 \\
\hline Peru & 15 & 31 & 59 & 67 & 70 \\
\hline Colombia & 12 & 25 & 41 & 55 & 66 \\
\hline Brazil & 11 & 26 & 34 & 39 & 45 \\
\hline Thailand & 13 & 17 & 29 & 30 & 55 \\
\hline Turkey & 14 & 27 & 35 & 54 & 56 \\
\hline Iran & 12 & 27 & 42 & 54 & 69 \\
\hline Algeria & 8 & 11 & 33 & 61 & 62 \\
\hline India & 20 & 26 & 30 & 44 & 49 \\
\hline Egypt & 16 & 35 & 50 & 76 & 74 \\
\hline Indonesia & 6 & 16 & 29 & 44 & 48 \\
\hline Morocco & 5 & 13 & 26 & 34 & 39 \\
\hline Bangladesh & 8 & 13 & 18 & 19 & 19 \\
\hline Pakistan & 11 & 13 & 14 & 21 & 26 \\
\hline Zaire & 3 & 9 & 24 & 24 & 26 \\
\hline Kenya & 2 & 9 & 20 & 23 & 24 \\
\hline Sudan & 3 & 7 & 16 & 23 & 13 \\
\hline Nigeria & 4 & 4 & 21 & 24 & 30 \\
\hline Tanzania & 2 & 3 & 3 & 5 & 5 \\
\hline Nepal & 6 & 10 & 21 & 31 & 38 \\
\hline Ethiopia & 0 & 4 & 8 & 13 & 31 \\
\hline Afghanistan & 1 & 7 & 10 & 9 & 21 \\
\hline
\end{tabular}

Continued- 
Appendix C (Continued-)

Primary School Enrolment in Sample Countries

\begin{tabular}{|c|c|c|c|c|c|}
\hline & 1960 & 1970 & 1980 & 1990 & 1995 \\
\hline Mexico & 80 & 104 & 122 & 115 & 115 \\
\hline Sri Lanka & 95 & 99 & 103 & 105 & 113 \\
\hline Korea & 94 & 103 & 110 & 105 & 101 \\
\hline Philippines & 95 & 108 & 113 & 113 & 114 \\
\hline Peru & 83 & 107 & 114 & 118 & 123 \\
\hline Colombia & 77 & 108 & 124 & 110 & 114 \\
\hline Brazil & 95 & 84 & 99 & 109 & 112 \\
\hline Thailand & 83 & 83 & 99 & 99 & 87 \\
\hline Turkey & 75 & 110 & 96 & 110 & 105 \\
\hline Iran & 41 & 72 & 87 & 110 & 99 \\
\hline Algeria & 46 & 76 & 94 & 100 & 107 \\
\hline India & 61 & 73 & 83 & 98 & 100 \\
\hline Egypt & 66 & 72 & 73 & 94 & 100 \\
\hline Indonesia & 71 & 80 & 107 & 115 & 114 \\
\hline Morocco & 47 & 52 & 83 & 67 & 83 \\
\hline Bangladesh & 47 & 52 & 63 & 79 & 92 \\
\hline Pakistan & 30 & 40 & 39 & 44 & 74 \\
\hline Zaire & 60 & 88 & 92 & 70 & 72 \\
\hline Kenya & 47 & 58 & 115 & 95 & 85 \\
\hline Sudan & 25 & 38 & 50 & 50 & 54 \\
\hline Nigeria & 36 & 37 & 119 & 86 & 89 \\
\hline Tanzania & 25 & 34 & 93 & 70 & 67 \\
\hline Nepal & 10 & 26 & 84 & 103 & 110 \\
\hline Ethiopia & 7 & 16 & 34 & 31 & 67 \\
\hline Afghanistan & 9 & 28 & 34 & 26.4 & 34.5 \\
\hline
\end{tabular}

Life Expectancy in Sample Countries

\begin{tabular}{|c|c|c|c|c|c|}
\hline & \multicolumn{4}{|c|}{ Life Expectancy in Sample Countries } & $\frac{\text { (Years) }}{715}$ \\
\hline Mexico & 57.0 & 61.9 & 66.7 & 70.0 & 71.5 \\
\hline Sri Lanka & 62.0 & 65.6 & 68.1 & 71.0 & 74.9 \\
\hline Korea & 54.4 & 62.2 & 66.8 & 71.0 & 75.5 \\
\hline Philippines & 52.8 & 58.8 & 61.0 & 64.0 & 67.7 \\
\hline Peru & 47.5 & 53.9 & 58.0 & 63.0 & 65.9 \\
\hline Colombia & 53.1 & 61.0 & 65.9 & 68.9 & 69.9 \\
\hline Brazil & 54.7 & 59.1 & 62.7 & 66.0 & 67.0 \\
\hline Thailand & 52.3 & 60.5 & 63.5 & 66.0 & 71.7 \\
\hline Turkey & 50.5 & 58.6 & 61.4 & 67.0 & 70.9 \\
\hline Iran & 49.6 & 54.5 & 60.1 & 63.0 & 69.2 \\
\hline Algeria & 47.0 & 53.3 & 59.3 & 65.0 & 69.6 \\
\hline India & 43.2 & 48.5 & 54.4 & 59.0 & 63.0 \\
\hline Egypt & 43.1 & 51.3 & 55.5 & 60.0 & 66.3 \\
\hline Indonesia & 41.2 & 47.3 & 54.8 & 62.0 & 66.0 \\
\hline Morocco & 46.7 & 51.9 & 58.0 & 62.0 & 65.4 \\
\hline Bangladesh & 37.3 & 41.6 & 48.5 & 52.0 & 58.4 \\
\hline Pakistan & 43.3 & 49.3 & 53.0 & 56.0 & 64.1 \\
\hline Zaire & 40.0 & 46.8 & 49.2 & 52.0 & 53.0 \\
\hline Kenya & 41.3 & 52.0 & 54.9 & 59.0 & 60.2 \\
\hline Sudan & 39.6 & 44.3 & 48.2 & 50.0 & 54.8 \\
\hline Nigeria & 38.7 & 44.5 & 47.7 & 52.0 & 53.9 \\
\hline Tanzania & 41.7 & 45.5 & 49.0 & 48.0 & 50.9 \\
\hline Nepal & 37.6 & 41.7 & 47.3 & 52.0 & 55.9 \\
\hline Ethiopia & 43.7 & 43.3 & 43.5 & 48.0 & 49.0 \\
\hline Afghanistan & 33.4 & 37.2 & 40.3 & 42.0 & 44.3 \\
\hline
\end{tabular}

Continued 


\section{Appendix C (Continued-)}

GNP Per Capita, in Sample Countries

\begin{tabular}{|c|c|c|c|c|c|}
\hline Countries & 1960 & 1970 & 1980 & 1990 & 1995 \\
\hline Mexico & 2160 & 2980 & 4112 & 5918 & 6769 \\
\hline Sri Lanka & 970 & 1282 & 1696 & 2405 & 3408 \\
\hline Korea & 690 & 1465 & 3110 & 6733 & 11594 \\
\hline Philippines & 870 & 1206 & 1671 & 2303 & 2762 \\
\hline Peru & 1720 & 2118 & 2608 & 2622 & 3940 \\
\hline Colombia & 1340 & 1946 & 2827 & 4237 & 6347 \\
\hline Brazil & 990 & 1716 & 2975 & 4718 & 5928 \\
\hline Thailand & 690 & 1204 & 2101 & 3986 & 7742 \\
\hline Turkey & 1260 & 1886 & 2824 & 4652 & 5516 \\
\hline Iran & 1840 & 2329 & 2948 & 3253 & 5480 \\
\hline Algeria & 1300 & 1635 & 2056 & 3011 & 5618 \\
\hline India & 530 & 633 & 755 & 1072 & 1422 \\
\hline Egypt & 500 & 810 & 1312 & 1988 & 3829 \\
\hline Indonesia & 490 & 783 & 1251 & 2181 & 3971 \\
\hline Morocco & 540 & 917 & 1558 & 2348 & 3477 \\
\hline Bangladesh & 760 & 908 & 1084 & 872 & 1382 \\
\hline Pakistan & 560 & 848 & 1284 & 1862 & 2209 \\
\hline Zaire & 310 & 348 & 392 & 367 & 355 \\
\hline Kenya & 470 & 618 & 812 & 1058 & 1438 \\
\hline Sudan & 670 & 765 & 873 & 949 & 1110 \\
\hline Nigeria & 550 & 688 & 861 & 1215 & 1270 \\
\hline Tanzania & 210 & 300 & 429 & 572 & 636 \\
\hline Nepal & 480 & 568 & 673 & 920 & 1145 \\
\hline Ethiopia & 290 & 310 & 332 & 369 & 455 \\
\hline Afghanistan & 670 & 684 & 698 & 714 & 700 \\
\hline
\end{tabular}

Infant Mortality in Sample Countries

\begin{tabular}{|c|c|c|c|c|c|}
\hline \multirow[b]{2}{*}{ Mexico } & \multicolumn{4}{|c|}{ Injant Mortality in sample countrles } & \multirow{2}{*}{$\frac{(\text { Per } 1,000)}{32.6}$} \\
\hline & 91.1 & 73.6 & 51.0 & 39.0 & \\
\hline Sri Lanka & 70.6 & 58.5 & 34.4 & 19.0 & 15.6 \\
\hline Korea & 78.3 & 50.1 & 25.8 & 17.0 & 9.8 \\
\hline Philippines & 105.8 & 75.0 & 52.2 & 41.0 & 38.8 \\
\hline Peru & 162.9 & 119.7 & 81.0 & 69.0 & 46.7 \\
\hline Colombia & 103.0 & 77.0 & 45.2 & 29.9 & 25.6 \\
\hline Brazil & 118.2 & 98.6 & 70.0 & 57.0 & 44.0 \\
\hline Thailand & 103.0 & 74.6 & 48.8 & 27.0 & 34.8 \\
\hline Turkey & 189.5 & 147.5 & 109.2 & 66.0 & 47.6 \\
\hline Iran & 163.0 & 136.2 & 91.6 & 88.0 & 45.2 \\
\hline Algeria & 165.0 & 144.0 & 97.6 & 67.0 & 33.5 \\
\hline India & 165.0 & 139.0 & 116.4 & 92.0 & 67.7 \\
\hline Egypt & 128.0 & 117.1 & 107.1 & 66.0 & 55.6 \\
\hline Indonesia & 149.9 & 120.9 & 90.0 & 61.0 & 51.0 \\
\hline Morocco & 160.5 & 136.4 & 99.2 & 67.0 & 54.6 \\
\hline Bangladesh & 159.0 & 150.3 & 131.6 & 105.0 & 78.8 \\
\hline Pakistan & 161.5 & 143.0 & 124.0 & 103.0 & 90.0 \\
\hline Zaire & 150.0 & 132.0 & 111.0 & 94.0 & 128.0 \\
\hline Kenya & 137.5 & 112.0 & 72.4 & 67.0 & 58.0 \\
\hline Sudan & 168.0 & 150.4 & 94.0 & 102.0 & 76.6 \\
\hline Nigeria & 183.4 & 158.0 & 99.4 & 98.0 & 79.8 \\
\hline Tanzania & 151.5 & 125.3 & 104.0 & 115.0 & 82.4 \\
\hline Nepal & 194.5 & 172.5 & 131.8 & 121.0 & 91.2 \\
\hline Ethiopia & 175.0 & 158.5 & 155.0 & 132.0 & 111.8 \\
\hline Afghanistan & 233.4 & 210.9 & 183.0 & 170.2 & 157.6 \\
\hline
\end{tabular}




\section{REFERENCES}

Adelman, I., and G. Dalton (1971) A Factor Analysis of Modernisation in Village India. Economic Journal 81:323S.

Jamal, Haroon, and Salman Malik (1988) Shifting Patterns in Development Rank Orderning: A Case Study of the Districts of Sindh Province. The Pakistan Development Review 27:2.

Pasha , Hafiz A., and Tariq Hasan (1982) Development Ranking of the Districts of Pakistan. Pakistan Journal of Applied Economics 1:2.

Pasha, Hafiz A., Salman Malik, and Haroon Jamal (1990) The Changing Profile of Regional Development in Pakistan. Pakistan Journal of Applied Economics 9:1.

Noorbakhsh, Farhad (1998) A Modified Human Development Index. World Development 26:3 517-528.

Noorbakhsh, Farhad (1998a) The Human Development Index: Some Technological Issues and Alternative Indices. Journal of International Development. 10:5 589605.

Ogwang-Tomson (1994) The Choice of Principle Variables for Computing the Human Development Index. World Development 22:12 2011-14.

Ghaus-Pasha, Aisha, et al. (1996) Social Development Ranking of Districts of Pakistan. Social Policy and Development Centre, Karachi. (Research Report No. 10.)

Ghaus-Pasha, Aisha, et al. (1998) Social Development in Pakistan, Annual Review. Karachi: Social Policy and Development Centre.

UNDP $(1991,1993,1998)$ Human Development Report. Washington, D. C.: UNDP. 


\section{Comments}

The paper by Ghaus-Pasha, Pasha and Ahmed deals with the critical issue of social development ranking of Pakistan relative to selected developing countries. The objective of the paper is to examine the issue whether the current low level of social indicators is a consequence of poor initial conditions or is it due to low rate of improvement relative to other countries? The authors select income, educational attainment, life expectancy and infant mortality rate as indicators of social development. Factor analysis technique is applied to construct index of social development for a sample of 25 countries with per capita income below US\$ 400 and population above 8-million in 1960. The results of the study show that Pakistan ranked 17 among the sample of 25 countries in 1960s but it was 23 and 18 out of 25 in 1980s and 1995 respectively. According to the authors, lack of government priority for social sectors is the major cause for the deterioration in social ranking of Pakistan. The study concludes by saying that, "if the situation is to be improved, concrete government effort at improving delivery mechanisms, improved costeffectiveness of expenditure and higher budgetary resources will have to be ensured. Moreover, civil society at large will have to play a complementary role, both in terms of enhancing awareness levels and provision of social services".

I agree with this conclusion, however, this is a general statement not a result based on the analysis conducted in the study. Furthermore, my other comments are as follows:

(1) The principal component technique orders the components on the basis of variance not in the order of importance as claimed by the authors.

(2) The problem of interpretation of different factor components are well documented.

(3) The factor loading matrix reported in Table 1 shows that the variables included in each factor changed over time. For example, in 1960s and 1970s, factor 1 did not include GDP-per capita but for 1980s and 1990s it is an important component of factor 1. Similarly, literacy was major component in factor 1 in 1960s and 1970s only. This creates not only the problem of interpretation but also the problem of comparability of the same factor over time.

(4) The role of the initial conditions is not discussed in detail.

(5) Emphasis on the role of public sector seems to assume that only the supply constraints are affecting literacy and education. The role of demand factors in ignored. 
(6) Ranking of a country gives it relative position. The country may have made significant progress in absolute terms. For example, the tables in Appendix $\mathrm{C}$ show significant improvements in health related indicators while the overall social development index shows deterioration in Pakistan's ranking.

Despite these problems the study indicates that overall situation regarding social development in Pakistan needs urgent policy actions as it is a prerequisite for economic growth and for improving population welfare.

Pakistan Institute of Development Economics,

Rehana Siddiqui Islamabad. 